\title{
Phosphoinositide 3-kinase $\gamma$ required for lipopolysaccharide-induced transepithelial neutrophil trafficking in the lung
}

\author{
J. Reutershan*\#, M.S. Saprito*, D. Wuๆ", T. Rückle ${ }^{+}$and K. Ley*,§
}

ABSTRACT: Phosphoinositide 3-kinase $\gamma(P I 3 K \gamma)$ is a critical mediator of directional cell movement. Here, we sought to characterise the role of $P I 3 K \gamma$ in mediating the different steps of polymorphonuclear leukocyte (PMN) trafficking in the lung.

In a murine model of lipopolysaccharide (LPS)-induced lung injury, PMN migration into the different lung compartments was determined in $\mathrm{PI} / 3 \mathrm{~K} \gamma$ gene-deficient $\left(\mathrm{PI} / 3 \mathrm{~K}^{-{ }^{-}}\right)$and wild-type mice. Bone marrow chimeras were created to characterise the role of $P I 3 K \gamma$ on haematopoietic versus nonhaematopoietic cells. A small-molecule $P I 3 K \gamma$ inhibitor was tested in vitro and in vivo.

PMN adhesion to the pulmonary endothelium and transendothelial migration into the lung interstitium was enhanced in $\mathrm{PI} 3 \mathrm{~K}^{-/-}$mice. However, transepithelial migration into the alveolar space was reduced in these mice. When irradiated $\mathrm{PI} 3 \mathrm{~K} \gamma^{-/-}$mice were reconstituted with bone marrow from wild-type mice, migratory activity into the alveolar space was restored partially. A small-molecule $P I 3 K \gamma$ inhibitor reduced chemokine-induced PMN migration in vitro when PMNs or epithelial cells, but not when endothelial cells, were treated. The inhibitor also reduced LPSinduced PMN migration in vivo.

We conclude that $P I 3 K \gamma$ is required for transepithelial but not for transendothelial migration in LPS-induced lung injury. Inhibition of $P I 3 K \gamma$ activity may be effective at curbing excessive PMN infiltration in lung injury.

KEYWORDS: Acute lung injury, chemotaxis, inflammation, polymorphonuclear leukocytes, transmigration

$\mathbf{R}$ ecruitment of polymorphonuclear leukocytes (PMNs) to inflamed tissues is an essential requirement of the innate immune response but can lead to organ damage when excessive and uncontrolled. In the lung, excessive PMN infiltration can result in acute lung injury (ALI) and acute respiratory distress syndrome (ARDS), a condition that can follow pneumonia, acid aspiration, major trauma or sepsis, and causes $\sim 75,000$ deaths per year in the USA alone [1]. Depletion of PMNs curbs experimental lung damage [2] but is not desirable in most patients because it induces impaired host defence. Although the pathogenicity of PMNs in ALI/ARDS has been impressively demonstrated, molecular mechanisms underlying PMN trafficking in the lung remain poorly understood [3]. This may explain why, to this day, there is no strategy for the modulation of PMN infiltration in humans and no therapy available for ALI/ARDS beyond mechanical ventilation and other supportive approaches [4]. The mortality of ARDS remains high at $35-40 \%$ [5].
Pulmonary infiltration with inflammatory leukocytes is initiated by activation of circulating PMNs, resulting in altered mechanical properties and enhanced migratory activity [6]. Initial contact between PMNs and pulmonary endothelium requires adhesion molecules in some ARDS models [7], but not in others [8]. Once activated PMNs adhere to the pulmonary capillaries, additional steps are required to initiate transendothelial migration into the lung interstitium and transepithelial migration into the alveolar space, including activation of chemokine receptors and structural rearrangement of adhesion molecules [9]. Cytoskeletal reorganisation of PMNs, and endothelial and epithelial cells is a prerequisite to facilitate directional movement of leukocytes to the lung.

The family of class I phosphoinositide 3-kinases (PI3Ks) are isoforms of heterodimeric lipidmodifying proteins that are involved in the regulation of numerous cell functions, including cell growth, proliferation, adhesion, motility and

\section{AFFILIATIONS}

${ }^{\star}$ Robert M. Berne Cardiovascular Research Center, University of Virginia, Charlottesville, VA, -Dept of Pharmacology, Yale University School of Medicine, New Haven, CT,

${ }^{\S}$ Division of Inflammation Biology, La Jolla Institute for Allergy \& Immunology, La Jolla, CA, USA "Dept of Anaesthesiology and Intensive Care Medicine, University of Tübingen, Tübingen, Germany. ${ }^{+}$Dept of Operational Excellence Research, Merck Serono International S.A., Geneva, Switzerland.

CORRESPONDENCE

J. Reutershan

Dept of Anesthesiology and Intensive Care Medicine University of Tübingen Hoppe-Seyler-Str. 3 72076 Tübingen Germany E-mail: joerg.reutershan@unituebingen.de

\section{Received:}

May 302009

Accepted after revision: Sept 082009 First published online: Sept 242009 
survival [10]. PI3K $\gamma$ is a class IB PI3K, consisting of a p110 $\gamma$ catalytic subunit and a 101-kD regulatory subunit (p101). $P I 3 K \gamma$ signalling is found downstream of different receptor types, including $G$ protein-coupled chemokine receptors. Activation of chemokine receptors leads to the release of the $G$ protein subunit $\beta \gamma$ that associates with the p110 adaptor protein and initiates translocation of $P I 3 K \gamma$ to the cell membrane, where it mediates the phosphorylation of posphatidylinositol (PI) 3,4bisphosphate to PI 3,4,5-trisphosphate [11]. PI 3,4,5-trisphosphate is an essential mediator of cell orientation and directional cell movement [12], thus making PI3K $\gamma$ a promising target in leukocyte-dependent inflammatory diseases [13].

Involvement of $P I 3 K \gamma$ in ALI has been implicated but study results have been ambiguous. In a model of ventilator-induced lung injury, $P I 3 K \gamma$ gene-deficient $\left(P I 3 K \gamma^{--}\right)$mice exhibited improved lung mechanics and reduced formation of hyaline membranes while release of chemotactic cytokines in the lung was unaltered [14]. In the same model, others demonstrated an attenuation in the activation of nuclear factor (NF)- $\kappa \mathrm{B}$ in inflammatory cells and a decrease in the release of inflammatory cytokines in mice pretreated with a nonselective PI3K inhibitor [15]. In contrast, $P I 3 K \gamma^{--}$mice were more susceptible to acute lung injury induced by intraperitoneal administration of Escherichia coli [16] or intratracheal application of pneumococcal virulence factor pneumolysin [17]. Pretreatment with the nonselective PI3K inhibitor wortmannin increased serum levels of pro-inflammatory cytokines and increased mortality in another sepsis model [18]. In different models of ALI, PMN recruitment and infiltration into the lungs of $P I 3 \mathrm{~K}^{-/-}$mice was found to be attenuated [19], increased [16] or similar [17] to wild-type mice. It is important to recognise that, in all these studies, single steps of PMN trafficking in the lung were not differentiated.

Functional expression of $P I 3 K \gamma$ in endothelial cells has recently been demonstrated and suggested to mediate selectin-dependent adhesion of leukocytes [19]. Whether PI3K $\gamma$ on pulmonary microvascular endothelial or epithelial cells is involved in adhesion or transmigration is unknown.

The current study was designed to elucidate the role of $P I 3 K \gamma$ for the different steps of PMN trafficking in the lung, i.e. recruitment from the peripheral blood and adherence to the pulmonary capillaries, transendothelial migration into the lung interstitium, and transepithelial migration into the alveolar space. We used gene-deficient mice and a selective smallmolecule inhibitor to block PI3K $\gamma$ function in vitro and in vivo. We created bone marrow chimeras to study $P I 3 K \gamma$ effects on haematopoietic versus nonhaematopoietic cells. Our results demonstrate a specific role of $P I 3 K \gamma$ in transepithelial neutrophil migration during ALI that might help to interpret conflicting results from previous studies.

\section{MATERIALS AND METHODS \\ Mice}

Wild-type male C57Bl/6 mice were obtained from Jackson Labs (Bar Harbor, ME, USA). Breeder pairs of $P I 3 K \gamma$ genedeficient mice (PI3K $\gamma^{-1-}, \mathrm{C} 57 \mathrm{Bl} / 6$ background) were provided by $\mathrm{D}$. $\mathrm{Wu}$ at the University of Connecticut (Farmington, CT, USA). Mice were bred, and deletion of the p110 subunit of PI3K $\gamma$ was confirmed by PCR [20]. Wild-type littermates
$\left(P I 3 \mathrm{~K}^{+/+}\right)$served as control animals. All animal experiments were approved by the Animal Care and Use Committee of the University of Virginia (Charlottesville, VA, USA). Mice were 8-12 weeks of age.

\section{Differential blood cell counts}

Increased blood cell counts in gene-deficient mice with targets that alter cell transmigration have been described [21] and will influence the analysis of migratory activity. To reveal possible differences between the different groups of mice, baseline differential blood counts were performed in $P I 3 \mathrm{~K}^{+/+}$and $P I 3 \mathrm{~K}^{-/-}$mice using an automatic analyser (Hemavet $850 \mathrm{FS}$; CDC Technologies, Oxford, CT, USA).

\section{Generation of chimeric mice}

Chimeric mice were generated by transferring bone marrow between $P I 3 \mathrm{~K}^{+/+}$and $P I 3 \mathrm{~K}^{-/-}$mice as described previously [22]. Briefly, recipient mice were lethally irradiated in two doses of $600 \mathrm{rad}$ each (separated by $4 \mathrm{~h}$ ). This regimen results in $>90 \%$ donor-derived neutrophils at 6 weeks of reconstitution. Bone marrow from donor mice was harvested from both femora and tibiae, and $\sim 5$ million cells were injected intravenously into recipient mice. Bone marrow transplantation (BMT) was performed in four groups of mice: 1) bone marrow from $P I 3 \mathrm{~K}^{-/-}$into $\mathrm{PI} 3 \mathrm{~K}^{+/+}{ }^{+/}$(chimeric mice express PI3K $\gamma$ on nonhaematopoietic cells only); 2) bone marrow from $\mathrm{PI} 3 \mathrm{~K}^{+/+}$into $\mathrm{PI} 3 \mathrm{~K}^{-/-}$(chimeric mice express $\mathrm{PI} \mathrm{K} \mathrm{\gamma} \gamma$ on haematopoietic cells only); 3) bone marrow from $P I 3 K_{\gamma}^{-/-}$into $P I 3 \mathrm{~K}^{-/-}$; and 4) bone marrow from $\mathrm{PI} 3 \mathrm{~K}^{+/+}$into $\mathrm{PI} 3 \mathrm{~K}^{+/+}$. Mice in groups 3 and 4 served as negative and positive controls for possible radiation effects. Chimeric mice were used for experiments 6 weeks after BMT.

\section{Small-molecule PI3K $\gamma$ inhibitor}

We evaluated the small-molecule PI3K $\gamma$ inhibitor AS-605240 (5quinoxalin-6-ylmethylene-thiazolidine-2,4-dione) (Merck Serono, Geneva, Switzerland) [23] for its efficiency to block PMN transmigration in vitro and in vivo. AS-605240 selectively inhibits $P I 3 K \gamma$ enzymatic activity, $P I 3 K \gamma$-mediated downstream signalling and chemotaxis [23]. Stock solutions were prepared in $0.5 \%$ carboxymethyl cellulose (CMC) and $0.25 \%$ Tween 20 in saline and used at indicated concentrations.

\section{In vitro transendothelial migration}

To test whether inhibition of neutrophil PI3K $\gamma$ is important in regulating migration, we conducted in vitro transmigration studies with PMNs and pulmonary endothelial cells (PECs) so that we could treat the cell types separately with AS-605240. PECs were harvested from wild-type male C57Bl/ 6 mice using a positive immunomagnetic selection for CD31 (Mec 13.3) (EasySep $_{\circledR}$ Biotin Selection Kit; StemCell Technologies, Vancouver, BC, Canada). PECs were cultured in DMEM (Dvaline instead of L-valine; Chemikon, Phillipsburg, NJ, USA) with $10 \%$ of fetal bovine serum (FBS), $20 \mathrm{mM}$ HEPES, $1 \%$ penicillin and streptomycin (Invitrogen, Carlsbad, CA, USA), and $50 \mu \mathrm{g} \cdot \mathrm{mL}^{-1}$ endothelial cell growth supplement (Sigma Co., St. Louis, MO , USA). Purity of PECs was confirmed by staining for von Willebrand factor (Abcam, Cambridge, MA, USA) and CD31 and their uptake of fluorescein isothiocyanate-labelled acetylated low-density lipoprotein (Biomedical Technologies Inc., Stoughton, MA, USA). Magnetic immunoseparation 
yielded a $>90 \%$ pure endothelial cell culture. Endothelial cells were plated on fibronectin-coated filters in a Transwell system (6.5 mm diameter, $3.0 \mu \mathrm{m}$ pore size; Corning Inc., Corning, NJ USA) and grown until confluent (72 h). Medium was replaced with phenol-free DMEM with 1\% FBS $2 \mathrm{~h}$ before the experiment. Filters without endothelial cells served as negative controls.

PMNs from $\mathrm{C} 57 \mathrm{Bl} / 6$ or $\mathrm{PI} 3 \mathrm{~K}^{---}$mice were isolated from bone marrow using a three layer Percoll gradient $(78,66$, and $54 \%)$ as previously described [9]. This technique yielded a cell purity of $>90 \%$. PMNs, endothelial cells or both were incubated with AS605240 at $15 \mu \mathrm{M}$ for $30 \mathrm{~min}$. This concentration has been previously shown to significantly reduce monocyte chemotactic protein-1-induced migration of mouse monocytes [23]. Negative controls were treated with vehicle only (CMC $0.5 \%$ and Tween $200.25 \%$ in saline). For the final $15 \mathrm{~min}$, PMNs were labelled with calcein AM (5 $\mu$ M; Molecular Probes, Carlsbad, CA, USA) and washed twice. Filters were moved to outer wells containing $400 \mu \mathrm{L}$ of phenol-free DMEM with or without chemokine (CXC motif) ligand (CXCL)2/3 (macrophage inflammatory protein-2, $200 \mathrm{ng} \cdot \mathrm{mL}^{-1}$; PeproTech Inc., Rocky Hill, NJ, USA). $2.5 \times 10^{5}$ PMNs were plated on filters with or without endothelial cells. Filters were incubated for $2 \mathrm{~h}$ at $37^{\circ} \mathrm{C}$ and fluorescence was measured in the bottom wells (excitation $485 \mathrm{~nm}$; emission $530 \mathrm{~nm}$ ).

\section{In vitro transendothelial and transepithelial migration of human cells}

PMNs from healthy donors were isolated by a two-layer Percoll gradient $(72 \%$ and $63 \%)$ as previously described [24]. The purity of the resulting cell population was $>95 \%$. Human A549 pulmonary epithelial cells (American Type Culture Collection, Manassas, VA, USA) were grown in RPMI containing $10 \%$ FBS, $1 \%$ epithelial cell growth supplement, and $1 \%$ penicillin/streptomycin solution. 100,000 epithelial cells were seeded on the collagen-coated undersurface of inverted Transwell filters and allowed to adhere for $2 \mathrm{~h}$ at $37^{\circ} \mathrm{C}$ in a humidified $5 \% \quad \mathrm{CO}_{2}$ incubator. Nonadherent cells were removed, filters were moved to wells containing culture medium, and cells were incubated for $72 \mathrm{~h}$ until a confluent monolayer was formed [25]. PMNs, A549 cells or both were incubated with AS-605240 at $15 \mu \mathrm{M}$ for $30 \mathrm{~min}$, and migratory activity was determined as described above. Negative controls were treated with vehicle only (CMC 0.5\% and Tween $200.25 \%$ in saline). In additional experiments, human pulmonary microvascular endothelial cells (HPMECs) (ScienCell Research Laboratories, Carlsbad, CA, USA) were plated on fibronectin-coated filters in a Transwell system, and transmigration of human PMNs was assessed as described above.

\section{Murine model of ALI}

Up to four mice were exposed to aerosolised lipopolysaccharide (LPS) in a custom-built cylindrical chamber $(20 \times 9 \mathrm{~cm})$ connected to an air nebuliser (MicroAir; Omron Healthcare, Vernon Hills, IL, USA). LPS from Salmonella enteritidis (Sigma Co.) was dissolved in $0.9 \%$ saline $\left(500 \mu \mathrm{g} \cdot \mathrm{mL}^{-1}\right)$ and mice inhaled LPS for $30 \mathrm{~min}$. As previously shown, this mimics several aspects of ALI, including PMN recruitment into all compartments of the lung, increase in vascular permeability
[26], release of chemokines and disruption of the pulmonary architecture [27]. Control mice were exposed to saline aerosol.

\section{In vivo inhibition of $P I 3 K \gamma$}

To evaluate PMN migration in vivo, wild-type and $\mathrm{PI} 3 \mathrm{~K}^{-1-}$ mice were intraperitoneally injected with AS-605240 $1 \mathrm{~h}$ prior to LPS exposure. The inhibitor was used at a concentration of $50 \mathrm{mg} \cdot \mathrm{kg}^{-1}$ as previously suggested [23]. Control mice received vehicle only (CMC $0.5 \%$ and Tween $200.25 \%$ in saline).

\section{PMN trafficking in the lung}

PMN recruitment into the different compartments of the lung (pulmonary vasculature, interstitium, alveolar airspace) was assessed as previously described [26]. Briefly, $24 \mathrm{~h}$ after LPS exposure (peak of LPS-induced accumulation of PMNs in the bronchoalveolar lavage fluid (BALF)), intravascular PMNs were labelled by an i.v. injection of Alexa 633-labelled GR-1. After $5 \mathrm{~min}$, mice were euthanised and nonadherent PMNs were removed from the pulmonary vasculature by flushing $10 \mathrm{~mL}$ of PBS at $25 \mathrm{cmH}_{2} \mathrm{O}$ through the spontaneously beating right ventricle. BALF was withdrawn and lungs were removed, minced and digested in the presence of excess unlabelled anti-GR-1 to prevent possible binding of the injected antibody to extravascular PMN. A cell suspension was prepared by passing the digested lungs through a $70 \mu \mathrm{m}$ cell strainer (BD Falcon, Bedford, MA, USA). Total cells in BALF and lung were counted and percentage of PMNs determined by flow cytometry. In the BALF, PMNs were identified by their typical appearance in the forward/sideward scatter and their expression of CD45 (clone 30-F11), 7/4 (clone 7/4), and GR-1 (clone RB6-8C5). In the lung, the expression of GR-1 was used to distinguish intravascular (CD45+7/4+GR-1+) from interstitial (CD45+7/4+GR-1-) PMNs, which were not reached by the injected antibody. In all experiments, isotype control antibodies were used to set the gates.

\section{Cytospins of BALF}

Cytospins of BALF from wild-type and $P I 3 \mathrm{~K}^{-1-}$ mice harvested $24 \mathrm{~h}$ after LPS exposure were prepared using a cytocentrifuge (Thermo Shandon, Waltham, MA, USA). Cytospun cells were stained (Diff-Quick staining; IMEB Inc., San Marcos, CA, USA), air dried and coverslipped.

\section{Pulmonary microvascular permeability}

Pulmonary microvascular permeability in wild-type and PI3 $\mathrm{K}^{--/}$mice was determined by measuring extravasation of Evans blue dye [28]. Evans blue $\left(20 \mathrm{mg} \cdot \mathrm{kg}^{-1}\right.$; Sigma-Aldrich, St Louis, MO, USA) was injected intravenously $30 \mathrm{~min}$ prior to euthanasia. Lungs were perfused with cold PBS through the spontaneously beating right ventricle to remove intravascular dye. Lungs were removed and Evans blue was extracted as previously described [29]. The absorption of Evans blue was measured at $620 \mathrm{~nm}$ and corrected for the presence of haem pigments: A620 $($ corrected $)=\mathrm{A} 620-(1.426 \times \mathrm{A} 740+0.030) \quad$ [30] Extravasated Evans blue was determined in the different animal groups $6 \mathrm{~h}$ after LPS (peak of LPS-induced increase in microvascular permeability) or saline inhalation and calculated against a standard curve (microgrammes Evans blue dye per gramme lung). In additional experiments, wild-type mice were pretreated with AS-605240 $\left(50 \mathrm{mg} \cdot \mathrm{kg}^{-1}\right.$ i.p. $)$ and microvascular permeability was determined. 


\section{BALF protein}

We measured LPS-induced accumulation of protein in the BALF of wild-type mice as an indicator of epithelial permeability. $6 \mathrm{~h}$ after LPS, protein in the BALF was determined by a colorimetric method against a standard curve according to the manufacturer's direction (bicinchoninic acid; Thermo Scientific, Rockford, IL, USA). Some mice were pretreated with AS-605240 $\left(50 \mathrm{mg} \cdot \mathrm{kg}^{-1}\right.$ i.p. $)$.

\section{Statistical analysis}

Statistical analysis was performed with JMP Statistical Software (version 7.0; SAS Institute Inc., Cary, NC, USA). Differences between the groups were evaluated by one way ANOVA followed by a post hoc Tukey test. Data were presented as mean \pm SD and $\mathrm{p}<0.05$ was considered statistically significant.

\section{RESULTS}

\section{Blood counts}

To reveal potential PMN count alterations in the $\mathrm{PI} 3 \mathrm{~K}^{--}$mice, baseline differential blood counts were determined using an automatic analyser. No differences in PMN counts were detected between wild-type and $\mathrm{PI} 3 \mathrm{~K}^{-/-}$mice. However, monocyte counts were elevated in $P I 3 \mathrm{~K}^{---}$mice $\left(0.6 \pm 0.3 \times 10^{3} \mu \mathrm{L}^{-1}\right.$ versus $0.3 \pm 0.2 \times 10^{3} \mu \mathrm{L}^{-1} ; \mathrm{p}<0.05$; table 1 ).

\section{PI3K regulates transepithelial PMN transmigration into the lung}

We used a flow cytometry-based method to detect PMNs in the different compartments of the lung of wild-type and $\mathrm{PI} 3 \mathrm{~K}^{-/-}$ mice. PMNs were identified by their typical appearance in the forward/side scatter and their expression of CD45 and 7/4 (fig. 1a). In the lung, we defined intravascular PMNs by their additional expression of GR-1+ (fig. 1b). In the BALF, all PMNs were identified by their expression of CD45, 7/4 and GR-1 (monoclonal antibodies added after harvesting) (fig. 1c). At baseline (no LPS), all PMNs in the lung were intravascular (fig. 1b left panels, 7/4+ and GR-1+, right upper square). LPS inhalation induced transendothelial migration into the lung interstitium as confirmed by the occurrence of GR-1- PMNs (fig. $1 \mathrm{~b}$, right panels, right lower square). In the BALF, no PMNs were detected at baseline (fig. c, left panels). Baseline PMN counts in lung interstitium and BALF did not differ

\begin{tabular}{|c|c|c|c|}
\hline & $P I 3 K \gamma^{+/+}$ & $P I 3 K \gamma^{-/-}$ & p-value \\
\hline Leukocytes $\times 10^{3} \mu \mathrm{L}^{-1}$ & $8.8 \pm 3.8$ & $11.3 \pm 4.9$ & 0.22 \\
\hline Neutrophils $\times 10^{3} \mu \mathrm{L}^{-1}$ & $1.6 \pm 0.6$ & $2.2 \pm 0.9$ & 0.08 \\
\hline Lymphocytes $\times 10^{3} \mu \mathrm{L}^{-1}$ & $6.8 \pm 3.2$ & $8.7 \pm 4.5$ & 0.28 \\
\hline Monocytes $\times 10^{3} \mu \mathrm{L}^{-1}$ & $0.3 \pm 0.2$ & $0.6 \pm 0.3$ & $<0.05$ \\
\hline Neutrophils \% & $18.9 \pm 4.2$ & $19.5 \pm 4.9$ & 0.76 \\
\hline Lymphocytes \% & $76.4 \pm 4.1$ & $73.9 \pm 4.9$ & 0.23 \\
\hline Monocytes \% & $3.6 \pm 1.8$ & $5.1 \pm 1.9$ & 0.10 \\
\hline \multicolumn{4}{|c|}{$\begin{array}{l}\text { Data are presented as mean } \pm \text { SD of eight mice, unless otherwise stated } \\
\text { Baseline differential cell counts were performed in phosphoinositide 3-kinase } \\
\text { gene-deficient }\left(P / 3 K \gamma^{-/-}\right) \text {and wild-type }\left(P / 3 K \gamma^{+/+}\right) \text {mice using an automatic } \\
\text { analyser. }\end{array}$} \\
\hline
\end{tabular}

between wild-type and $\mathrm{PI} 3 \mathrm{~K} \gamma^{-/-}$mice; however, $\mathrm{PI} 3 \mathrm{~K} \gamma^{-/-}$mice demonstrated a higher PMN accumulation in the pulmonary microvasculature (fig. 2a).

LPS inhalation induced significant PMN recruitment into all compartments of the lung of wild-type and $P I 3 \mathrm{~K}^{---}$mice (figs 1 and 2). LPS-induced PMN accumulation in the pulmonary circulation was significantly higher in $\mathrm{PI} 3 \mathrm{~K}^{--/}$compared with wild-type mice at $24 \mathrm{~h}$ after LPS $\left(2.2 \pm 0.6 \times 10^{6}\right.$ versus $1.1 \pm 0.3 \times 10^{6} ; \mathrm{p}<0.05$; fig. $\left.2 \mathrm{a}\right)$. In addition, $\mathrm{PMN}$ migration into the interstitium was significantly higher in $\mathrm{PI} 3 \mathrm{~K}^{-/-}$mice $\left(2.4 \pm 0.4 \times 10^{6}\right.$ versus $1.5 \pm 0.4 \times 10^{6} ; \mathrm{p}<0.05$; fig. $\left.2 \mathrm{~b}\right)$. Despite higher PMN counts in the lung tissue (intravascular and interstitial), PMN migration into the alveolar space (BALF; fig. 2c) was reduced in $P I 3 K^{-/-}$mice $\left(1.1 \pm 0.2 \times 10^{6}\right.$ versus $\left.2.4 \pm 0.6 \times 10^{6} ; \mathrm{p}<0.05\right)$, suggesting that in vivo, $\mathrm{PI} 3 \mathrm{~K} \gamma^{-/-}$is required for transepithelial but not for transendothelial migration in the lung. Reduced PMN counts in the alveolar airspace of $P I 3 \mathrm{~K}^{-1-}$ was confirmed by cytospin of BALF (fig. 2e).

\section{PMN trafficking in chimeric mice}

To characterise the role of $P I 3 K \gamma$ on haematopoietic and nonhaematopoietic cells, we created chimeric mice by transferring bone marrow between wild-type and $P I 3 \mathrm{~K}^{-/-}$mice. LPSinduced PMN migration in control mice that received bone marrow from mice of the same genotype was similar to wildtype (positive control group) or $\mathrm{PI} 3 \mathrm{~K}^{-/-}$(negative control group) mice, respectively (fig. 3). In mice that expressed $P I 3 K \gamma$ on nonhaematopoietic cells only, transepithelial migration into the BALF was significantly reduced $\left(0.8 \pm 0.2 \times 10^{6}\right.$ versus $2.4 \pm 0.5 \times 10^{6} ; \mathrm{p}<0.05$; fig. $\left.3 \mathrm{c}\right)$. The reduction was to a level similar to mice of the negative control group (bone marrow of PI3K $\gamma^{-/-}$into PI3K $\gamma^{-/-}$mice; $0.8 \pm 0.2 \times 10^{6}$ versus $0.9 \pm 0.2 \times 10^{6}$; nonsignificant). Consistent with a defect in transepithelial migration, intravascular and interstitial PMN counts were elevated in these mice (fig. $3 a$ and b). It is possible that neutrophils get "backed up" in the intravascular and interstitial compartment when their transepithelial migration is impaired in $\mathrm{PI} 3 \mathrm{~K}^{-/-}$mice. When $\mathrm{PI} 3 \mathrm{~K}^{-/-}$mice were reconstituted with bone marrow from wild-type mice, transepithelial migration was only partially restored $\left(1.6 \pm 0.3 \times 10^{6}\right.$ versus $2.4 \pm 0.5 \times 10^{6}$ in mice that express $P I 3 K \gamma$ on all cells; $\mathrm{p}<0.05$; fig. $3 \mathrm{c}$ ). Intravascular and interstitial PMN counts in $P I 3 \mathrm{~K}^{-/-}$mice reconstituted with bone marrow from wild-type mice were not different from wild-type mice reconstituted with bone marrow of wild-type mice, but significantly less than in mice of the negative control group or in $P I 3 \mathrm{~K}^{--1}$ mice. This finding supports the hypothesis that $P I 3 K \gamma$ on nonhaematopoietic cells is involved in transepithelial migration of PMNs.

\section{AS-605240 inhibits in vitro transmigration}

To evaluate its efficiency to inhibit chemokine-induced PMN migration in vitro, we incubated PMNs from wild-type C57Bl/ 6 or $P I 3 K^{-1-}$ mice with the small-molecule PI3K $\gamma$ inhibitor AS$605240(15 \mu \mathrm{M})$, and allowed them to migrate through a Transwell filter. Migratory activity of $P I 3 \mathrm{~K}^{-/-}$PMNs was significantly reduced compared with wild-type PMNs. AS605240 reduced CXCL2/3-stimulated migration of wild-type but not of $\mathrm{PI} 3 \mathrm{~K}^{-1-}$ PMNs by $>60 \%$ ( $\mathrm{p}<0.05$ versus untreated control) (fig. 4a), confirming a specific effect of AS-605240 on this subtype of PI3K. 

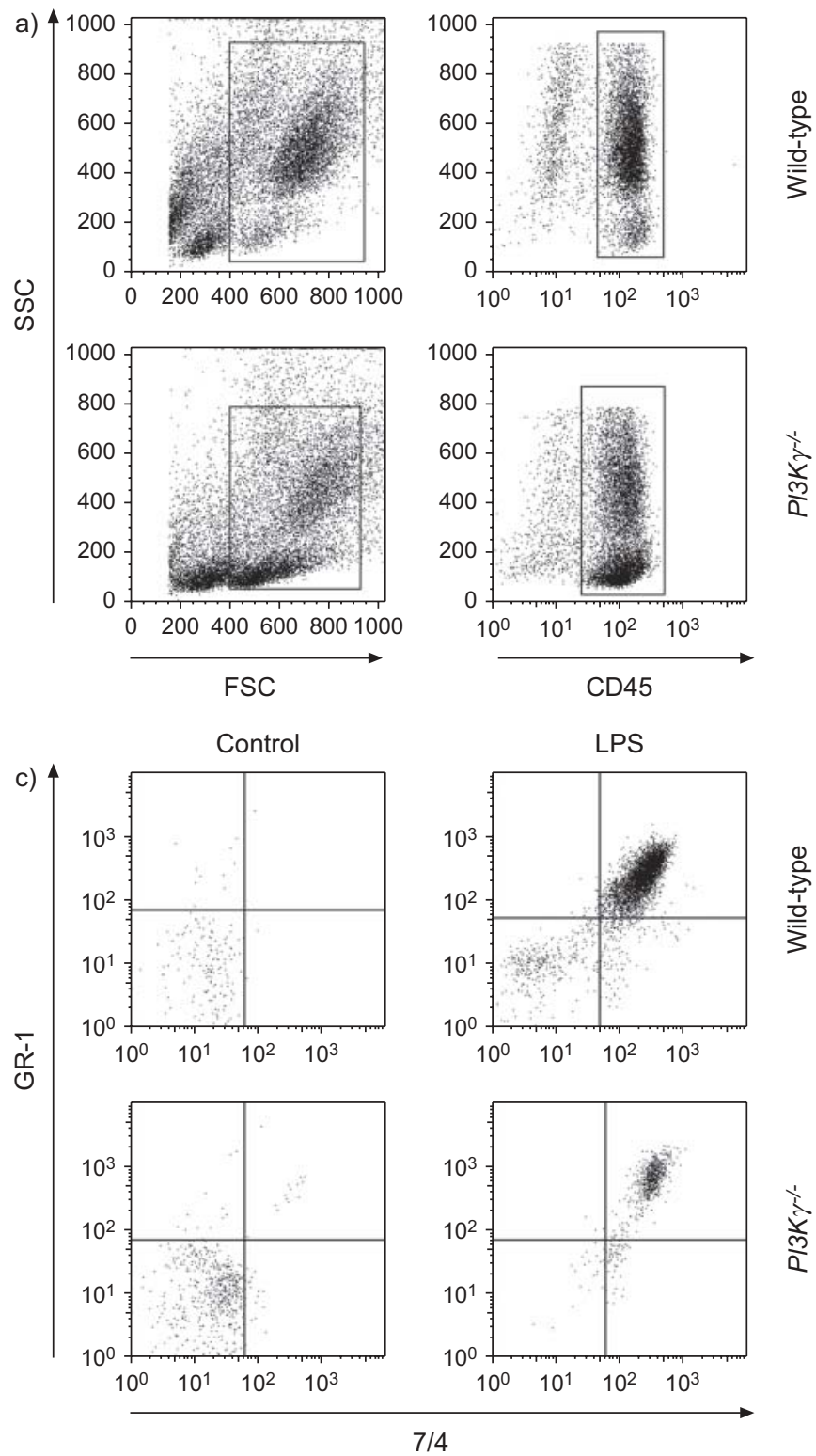

Next, we sought to determine the effect of AS-605240 on PECs versus PMNs. PECs were grown to confluence, and CXCL2/3induced transendothelial PMN migration was measured. PMNs, PECs or both cell types were pretreated with the PI3K $\gamma$ inhibitor as indicated.

CXCL2/3-stimulated migration through the endothelial layer was significantly reduced when PMNs were pretreated with AS-605240 ( $>50 \%$ reduction; $p<0.05$ versus untreated control; fig. 4b). No effect was observed when PECs were pretreated with the PI3K $\gamma$ inhibitor. When both PMNs and PECs were pretreated simultaneously, migration was similar to wells in which only PMNs were pretreated, indicating that $P I 3 K \gamma$ in PMNs but not in endothelial cells is required for chemokineinduced endothelial transmigration (fig. 4b).

Our in vivo experiments implicated a distinct role of PI3K $\gamma$ for the transepithelial migration. We therefore hypothesised that

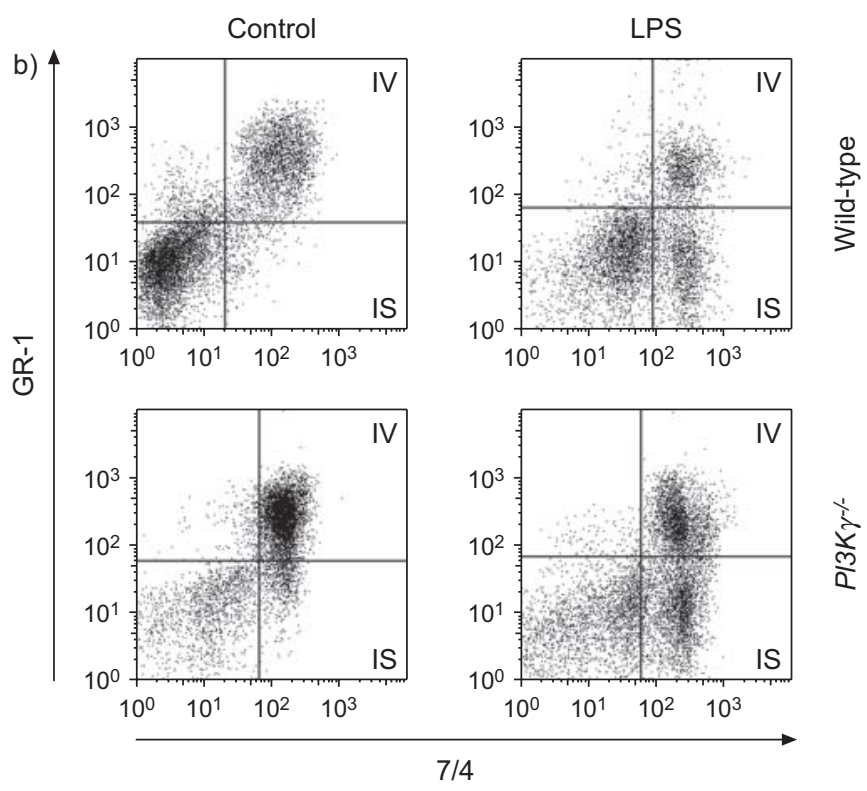

FIGURE 1. Lipopolysaccharide (LPS)-induced accumulation of polymorphonuclear leukocytes (PMNs) in the different compartments of wild-type and phosphoinositide 3-kinase gene-deficient $\left({\mathrm{P} / 3 \mathrm{~K}^{-1-}}^{-1}\right)$ mice $24 \mathrm{~h}$ after LPS. a) PMNs are identified by their typical appearance in the forward/side scatter and their expression of CD45 and 7/4. b) In the lung, only intravascular PMNs are also labelled by GR-1. c) In bronchoalveolar lavage fluid, all PMNs are identified by their expression of CD45, GR-1 and 7/4. IV: intravascular; IS: interstitial. Representative plots from one experiment in each group. SSC: side scatter; FSC: forward scatter

blocking $P I 3 K \gamma$ in A549 cells would reduce transepithelial PMN migration in vitro. CXCL2/3-induced transepithelial migration was significantly reduced when PMNs were pretreated with AS-605240, similar to the transendothelial migration ( $46 \%$ reduction; $\mathrm{p}<0.05$ versus untreated control; fig. 4c). When PI3K $\gamma$ was blocked in A549 cells alone, PMN migration was reduced by $26 \% \quad(p<0.05$ versus untreated control). This was in contrast to our findings with endothelial cells where blocking PI3K $\gamma$ did not affect migration and supports our hypothesis that epithelial PI3K $\gamma$ is involved in PMN trafficking in the lung. Blocking PI3K $\gamma$ in A549 cells and PMNs did not further decrease migration, indicating that PI3K $\gamma$ on PMNs limits PI3K $\gamma$-dependent trafficking in our system. This is in line with our in vivo findings (fig. 3c).

To reveal potential species differences with respect to PI3Kdependent transmigration of PMNs, we repeated the in vitro transmigration assays with HPMECs. In analogy to our 

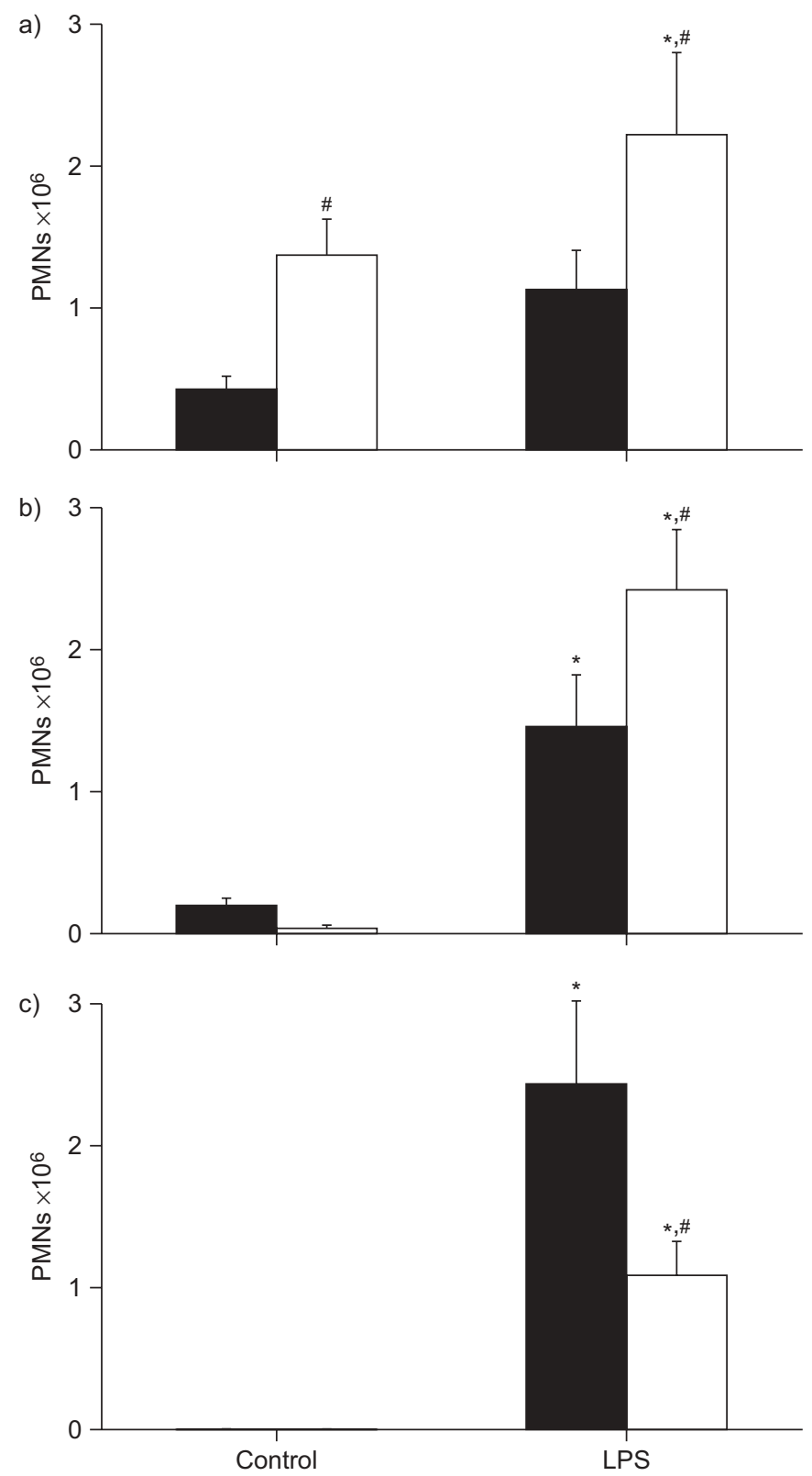
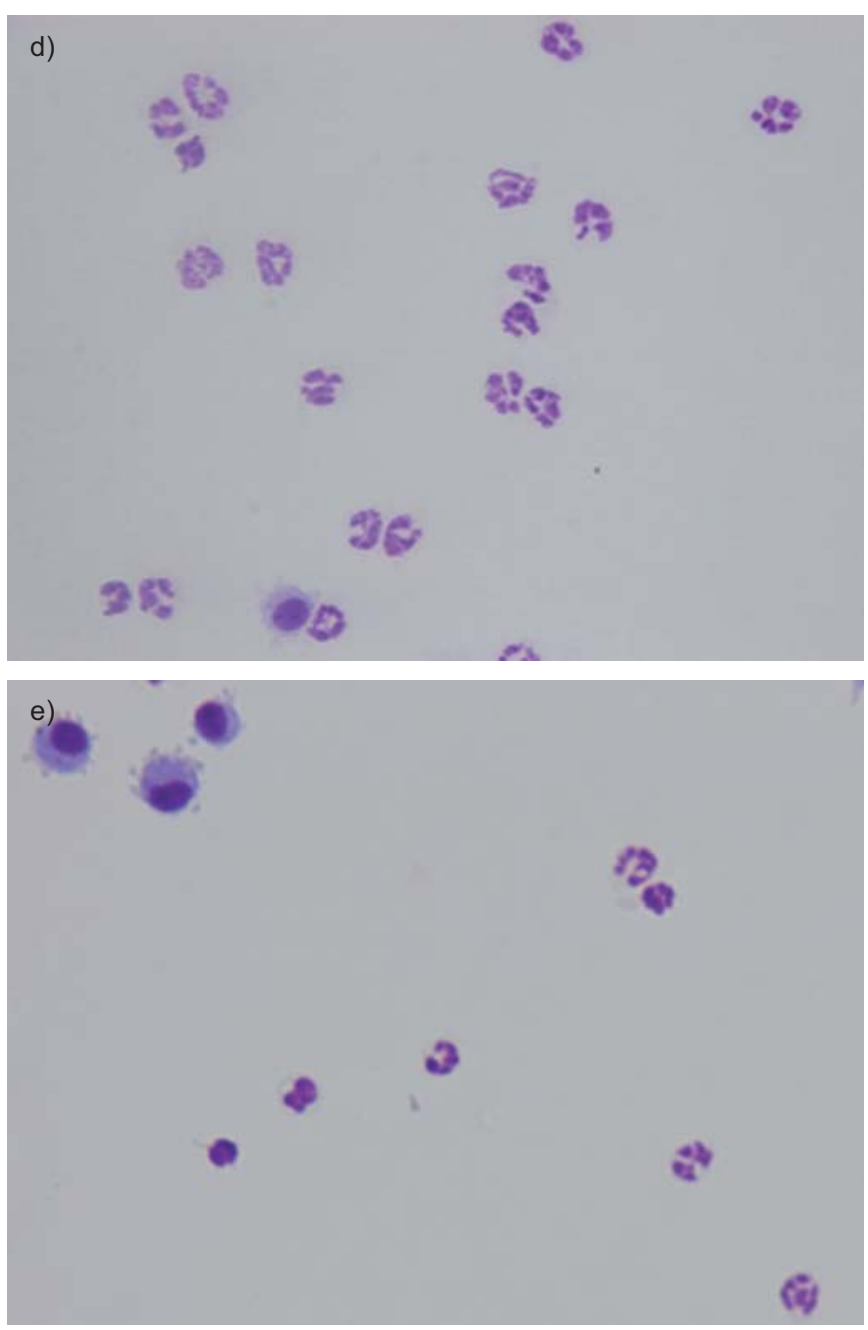

FIGURE 2. Lipopolysaccharide (LPS)-induced migration of polymorphonuclear leukocytes (PMNs) into the different lung compartments of wild-type ( $\mathbf{\square})$ and phosphoinositide 3-kinase gene-deficient $\left(P / 3 \mathrm{Kr}^{--}\right)(\square)$ mice. Accumulation of PMNs in a) the vasculature, b) the lung interstitium and c) the bronchoalveolar space were analysed. Cytospins of LPS-exposed bronchoalveolar lavage fluid in d) wild-type and e) $P / 3 K \gamma^{-1-}$ mice are shown to illustrate quantitative data. Values are presented as mean \pm SD of five experiments. *: $p<0.05$ versus negative control without LPS; ${ }^{*}: p<0.05$ versus wild-type mice within the same treatment group ( \pm LPS).

findings with murine cells, inhibition of PI3K in HPMEC did not affect PMN migration (fig. 4d), suggesting that both species are comparable.

\section{Effects of AS-605240 on in vivo transmigration}

Next, we sought to determine the effects of AS-605240 $\left(50 \mathrm{mg} \cdot \mathrm{kg}^{-1}\right)$ on LPS-induced PMN migration in vivo. Wildtype and $P I 3 \mathrm{~K}^{-1-}$ mice received AS-605240 $30 \mathrm{~min}$ prior to LPS exposure. After $24 \mathrm{~h}$, accumulation of PMNs in the different compartments of the lung was determined by flow cytometry. In wild-type mice, LPS-induced influx of PMNs into the BALF was significantly reduced by the pretreatment with AS-605240 $\left(1.6 \pm 0.3 \times 10^{6}\right.$ versus $2.6 \pm 0.6 \times 10^{6} ; \mathrm{p}<0.05 ;$ fig. 5$)$. The inhibitor did not reduce recruitment of PMNs to the pulmonary vasculature or transendothelial migration into the interstitium. In addition, the inhibitor exhibited no effects on LPS-induced $\mathrm{PMN}$ migration in $\mathrm{PI} 3 \mathrm{~K}^{---}$mice, supporting its specificity for $P I 3 K \gamma$.

\section{Microvascular permeability and BALF protein}

Disturbance of endothelial integrity and efflux of protein-rich fluid into the lung tissue is one of the critical events in the early development of ARDS that accompanies PMN infiltration. We therefore determined the role of $P I 3 K \gamma$ in LPS-induced 

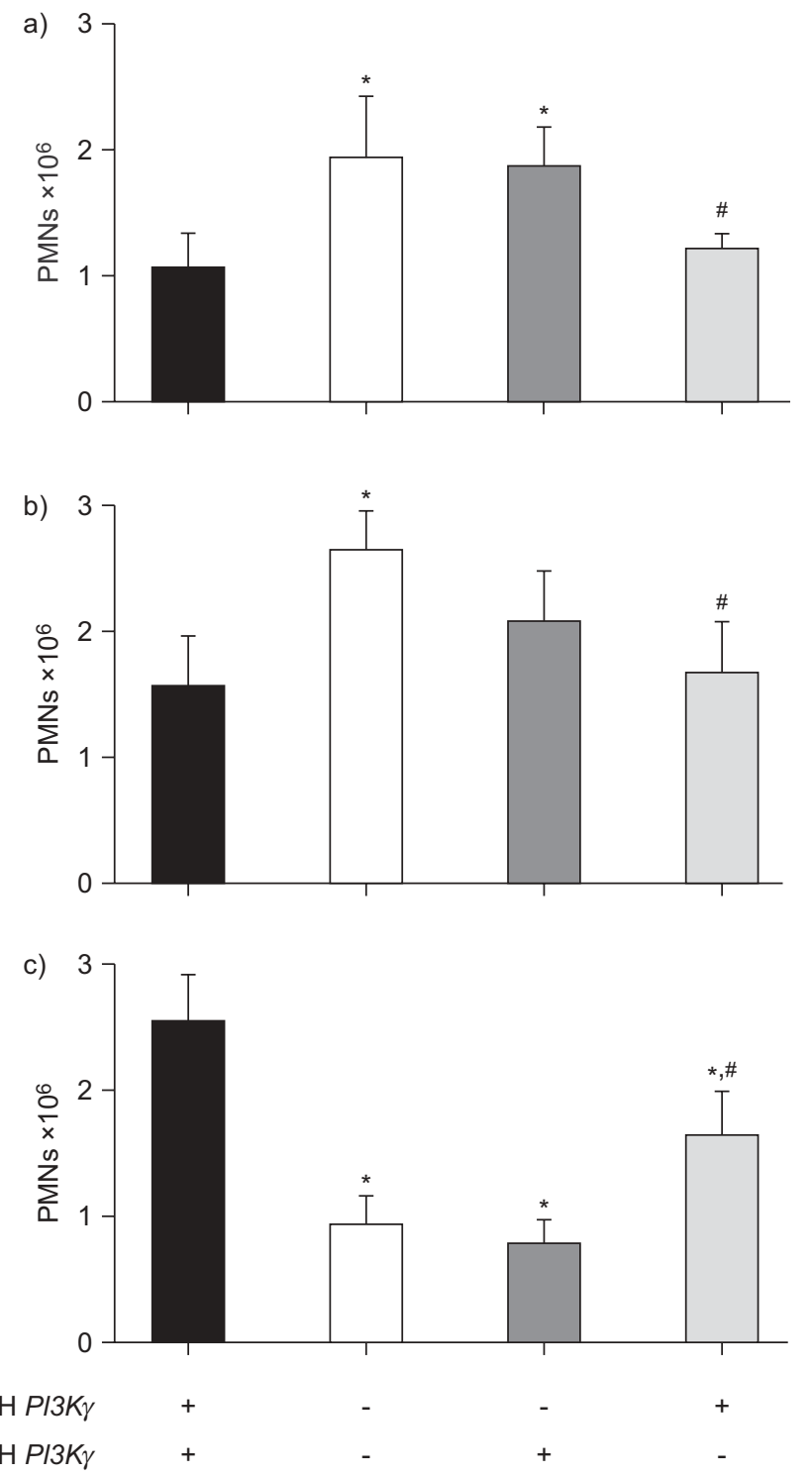

FIGURE 3. Haematopoietic $(H)$ and nonhaematopoietic (non-H) cell phosphoinositide 3-kinase $\gamma(P / 3 K \gamma)$ participation in lipopolysaccharide-induced polymorphonuclear leukocyte (PMN) trafficking in the lung. Accumulation of PMNs in a) the vasculature, b) the lung interstitium and c) the bronchoalveolar space were analysed in chimeric mice (grey bars). Values are presented as mean $\pm \mathrm{SD}$ of five experiments. ${ }^{*}: p<0.05$ versus positive control (bone marrow transfer between wildtype mice: $\mathbf{\square}) ;{ }^{\#}: p<0.05$ versus negative control (bone marrow transfer between

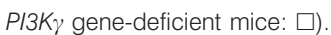

microvascular permeability assessed by the extravasation of Evans blue and protein accumulation in the alveolar space as indicators of endothelial and epithelial permeability, respectively. LPS induced a significant increase in microvascular permeability in wild-type $\left(394 \pm 33\right.$ versus $151 \pm 11 \mu \mathrm{g} \cdot \mathrm{g}^{-1}$ lung; $\mathrm{p}<0.05)$ and $P I 3 \mathrm{~K}^{-/-}$mice $\left(568 \pm 153\right.$ versus $279 \pm 97 \mu \mathrm{g} \cdot \mathrm{g}^{-1}$ lung; $\mathrm{p}<0.05$; fig. 6a). Although both baseline and LPS-induced microvascular permeability tended to be higher in $\mathrm{PI} 3 \mathrm{~K}^{-/-}$ mice, differences were not significant. Pretreatment with AS605240 did not prevent LPS-induced microvascular permeability in wild-type or PI3K $\gamma^{-/-}$mice. In addition, LPS-induced protein efflux into the alveolar space was not affected by inhibition of $\mathrm{PI} 3 \mathrm{~K} \gamma$ (fig. 6b). This suggests a distinct role of PI3K $\gamma$ for cell trafficking in our model.

\section{DISCUSSION}

The present study was designed to characterise the role of $P I 3 K \gamma$ in the distinct steps of PMN trafficking in the lung. In a murine model of ALI/ARDS, PI3K $\gamma$ was required for the transepithelial migration of PMNs from the lung interstitium into the alveolar airspace, while adhesion to and migration through the pulmonary endothelium remained unaffected in the absence of $P I 3 K \gamma$. Transmigration was mainly dependent on $P I 3 K \gamma$ on bone marrow-derived cells, although $P I 3 K \gamma$ on nonhaematopoietic cells contributed to the transepithelial migration of PMNs. The small-molecule PI3K $\gamma$ inhibitor AS605240 reduced PMN migration in vitro and PMN infiltration into the lung in vivo.

The key role of $P I 3 K \gamma$ in migration of leukocytes to inflamed tissue has led to several experimental studies that sought to identify the effects of $P I 3 K \gamma$-involving pathways in ALI, a disease that is largely characterised by the infiltration of inflammatory cells. Consistent with the hypothesis that inhibition of PI3K $\gamma$ attenuates ALI, PURI et al. [19] found that LPS-induced PMN migration into the BAL was almost

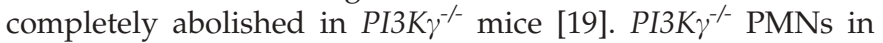
the lungs exhibited diminished activation of NF- $\kappa B$ and expression of pro-inflammatory chemokines interleukin-1 $\beta$ and tumour necrosis factor (TNF)- $\alpha$ [31]. Similar results were found in a model of ventilator-induced lung injury where blocking PI3K with a nonselective PI3K inhibitor reduced nuclear translocation of NF- $\mathrm{KB}$ and the release of interleukin-6 and macrophage inflammatory protein-2 in the lung [15]. In a similar model, $\mathrm{PI} 3 \mathrm{~K}^{-/-}$mice exhibited less lung damage as assessed by respiratory mechanics and the formation of hyaline membranes [14]. In that study, effects of the $P I 3 K \gamma$ pathway were independent of the release of chemotactic chemokines, but the authors observed an increased apoptotic activity in pulmonary cells of $P I 3 \mathrm{~K}^{-/-}$mice while cell necrosis was reduced in these mice.

The role of the PI3K pathway in mediating apoptosis is well established [32]. However, the role of apoptosis in the pathophysiology of inflammatory diseases remains controversial. Increased apoptosis, particularly in lymphoid tissue, contributes to immune suppression and organ failure that occurs during sepsis [33]. Conversely, apoptosis, in contrast to necrosis, generally does not produce inflammation and tissue damage [34]. In lung injury, cell necrosis rather than apoptosis is associated with an inflammatory response and inversely correlates with lung function [35]. In addition, PI3K $\gamma$-dependent pathways seem notably important for the integrity of the alveolar epithelium [36], consistent with our finding that $P I 3 K \gamma$ was mediating the epithelial but not endothelial barrier function in the lung. BONNANS et al. [37] identified an endogenous PI3K inhibitory pathway that is initiated by the production of presqualene diphosphate (PSDP). In acidinduced lung injury, PSDP is suppressed and PI3K $\gamma$ activity increased. Consequently, pretreatment with a PSDP analogue reduced acid-induced PMN infiltration and lung tissue damage. 

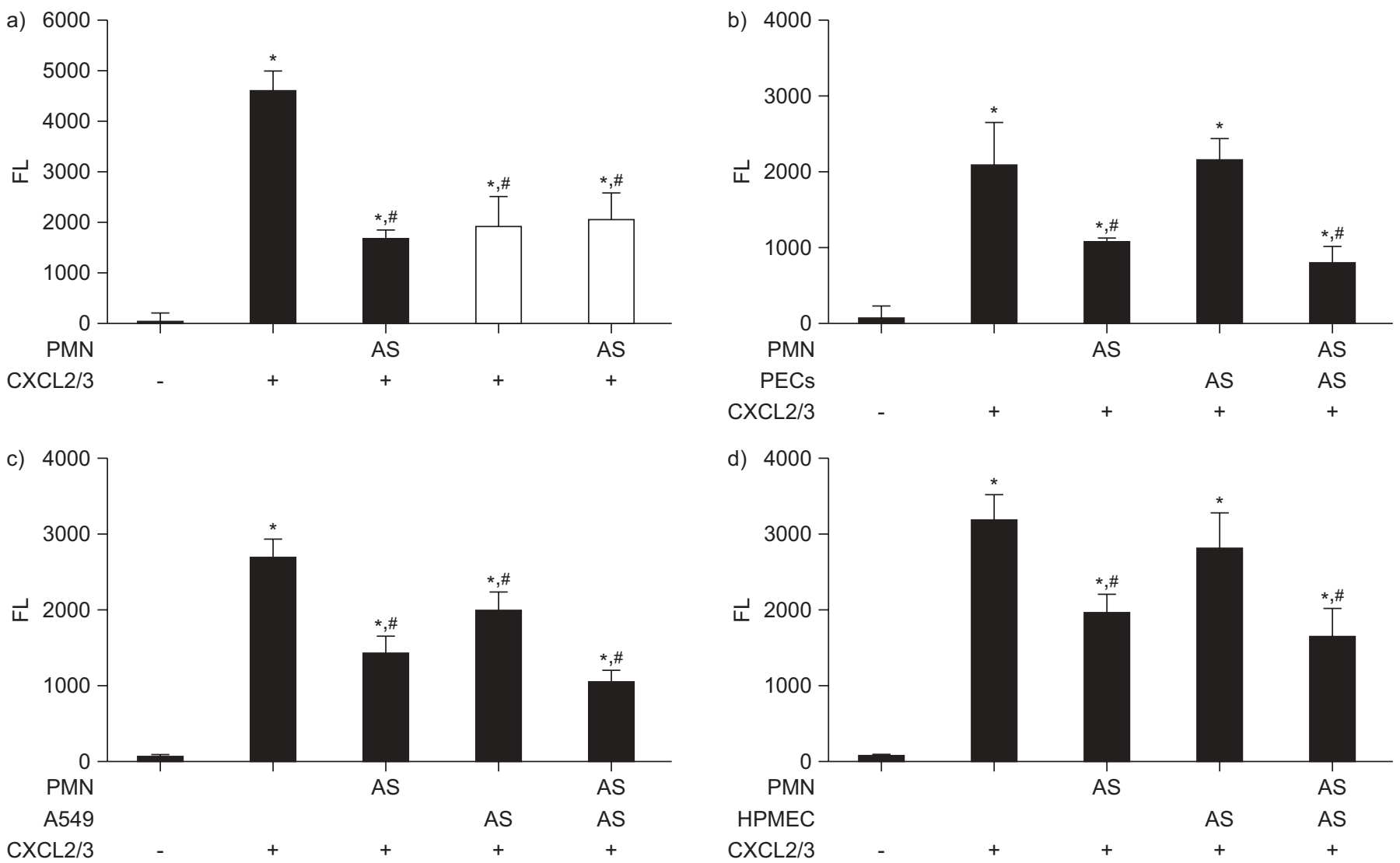

FIGURE 4. The effect of the phosphoinositide 3-kinase $\gamma(P I 3 K \gamma)$ inhibitor AS-605240 (AS) on chemokine-induced transmigration was evaluated in vitro. Transmigration across a) a Transwell filter alone or b) a confluent layer of cultured murine pulmonary endothelial cells (PECs), c) human A549 cells or d) human pulmonary microvascular endothelial cells (HPMECs) in a Transwell filter was significantly reduced when polymorphonuclear leukocytes (PMNs) were pretreated with AS-605240. No effect was seen

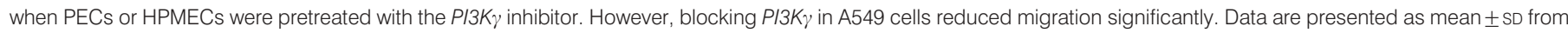
three separate experiments (each in duplicate). $\mathbf{\square}$ : wild-type; $\square:$ : PI $K \gamma \gamma$ gene deficient. FL: fluorescence. *: $p<0.05$ versus negative control without chemokine; ${ }^{*}: p<0.05$ versus positive control without inhibitor.

However, beneficial effects of $P I 3 K \gamma$ inhibition in ALI did not remain indisputable. Not inhibition, but activation of PI3Kdependent pathways was found to promote lung epithelial repair in vitro induced by Fas-induced apoptosis [38] or mechanical injury [39]. In E. coli-induced sepsis, pulmonary PMN accumulation and microvascular permeability was pronounced in $P I 3 \mathrm{~K}^{-/-}$mice and associated with increased expression of CD47 and $\beta_{3}$-integrins [16]. Consistent with our findings, the authors observed increased PMN counts in the lung interstitium by using morphometric analyses and suggested that upregulation of the CD47-associated $\beta_{3}$-integrin complex led to increased adhesion of PMNs within the extracellular matrix and accumulation of PMNs in the lung interstitium. Transepithelial migration into the BALF was not determined in that study. In endotoxaemic mice, nonspecific PI3K inhibition led to a state of hypercoagulation, increased release of cytokines and, most notably, increased mortality [40]. In addition, anti-inflammatory effects of lipoic acid or glucan phosphate, both stimulating the PI3K pathway, were abolished when PI3K signalling was blocked [41], indicating that the PI3K pathway is a physiological inhibitor of inflammation in endotoxaemia and sepsis. In a model of S. pneumoniae-induced lung inflammation, bacterial clearance was significantly reduced when PI3K signalling was inhibited, most likely due to a defect in respiratory burst and insufficient production of reactive oxygen species [17]. In addition, $\mathrm{PI} 3 \mathrm{~K}^{-/-}$ mice failed to sufficiently recruit monocytes into the lung while PMN trafficking remained unaffected, confirming cell-specific effects of PI3K signalling observed by others [42].

The activation of multiple PI3K-dependent pathways with opposing effects might be one explanation for the apparent discrepancies seen in lung injury in different studies $[14,16,17$, $40,43]$. It is also important to mention that so far, the use of nonselective PI3K inhibitors such as wortmannin or LY294002 hampered the validation of the $P I 3 K \gamma$ pathway as a therapeutic target.

Signalling of endothelial PI3K is known to mediate cell migration, vascular permeability and angiogenesis [44, 45] and has, therefore, been implicated as a promising target in various malignant diseases [46]. However, involvement of endothelial $P I 3 K \gamma$ in inflammatory responses has been controversial. $P I 3 K \gamma$ was not required for TNF-induced upregulation of $N F-\kappa B$ in human umbilical vein endothelial cells (HUVECs) [47]. Others, however, demonstrated PI3K $\gamma$-dependent NF- $\kappa \mathrm{B}$ binding to the intercellular adhesion molecule 

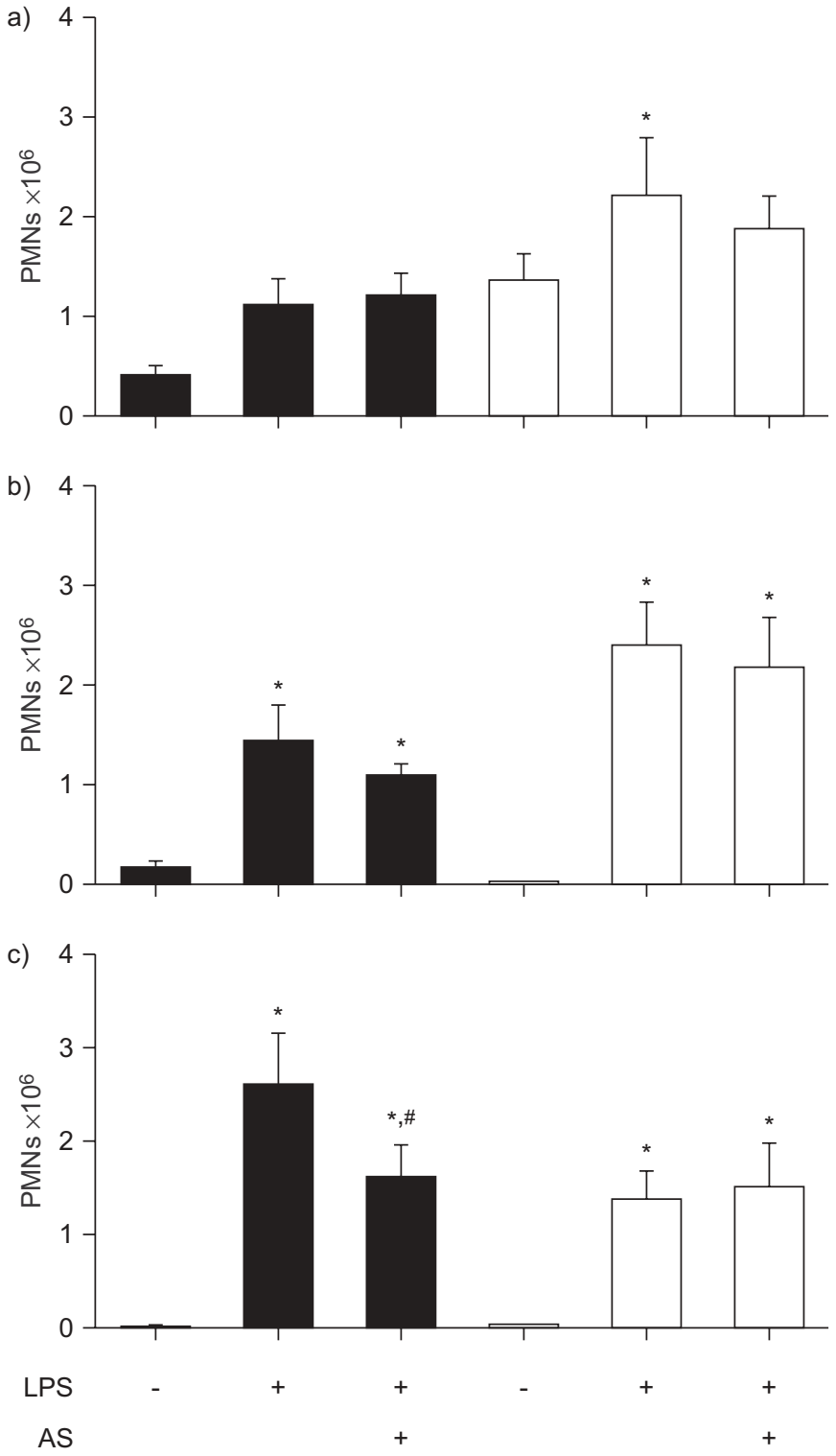

FIGURE 5. Effect of the phosphoinositide 3-kinase $\gamma(P / 3 K \gamma)$ inhibitor AS605240 (AS) on lipopolysaccharide (LPS)-induced polymorphonuclear leukocyte (PMN) migration into the different compartments of the lung. Accumulation of PMNs in a) the vasculature, b) the lung interstitium and c) the bronchoalveolar space of

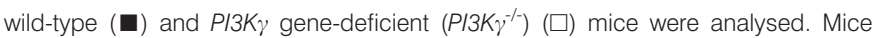
were pretreated $30 \mathrm{~min}$ prior to LPS exposure. AS-605240 significantly inhibited PMN migration in wild-type mice. No effect was seen in $\mathrm{P} / 3 \mathrm{~K}^{-1-}$ mice. Data are presented as mean $\pm S D$ of five experiments. ${ }^{*}: p<0.05$ versus negative control without LPS; ${ }^{*}: p<0.05$ versus LPS without $P / 3 K \gamma$ inhibitor.

(ICAM)-1 promoter in pulmonary microvascular endothelial cells that was required for static adhesion of PMNs [48]. Chemokine-induced leukocyte adhesion was reduced in $P I 3 \mathrm{~K}^{-/-}$mice and in lethally irradiated wild-type mice that had been reconstituted with bone marrow from $P I 3 \mathrm{~K}^{-1-}$ mice [49]. Interestingly, impairment of adhesion was not as severe when $\mathrm{PI} 3 \mathrm{~K}^{-/-}$deletion was confined to bone marrow-derived cells ( $50 \%$ versus $80 \%$ reduction), underlining a contribution of nonleukocyte $P I 3 K \gamma$. In our model, $P I 3 K \gamma$-deficiency led to a
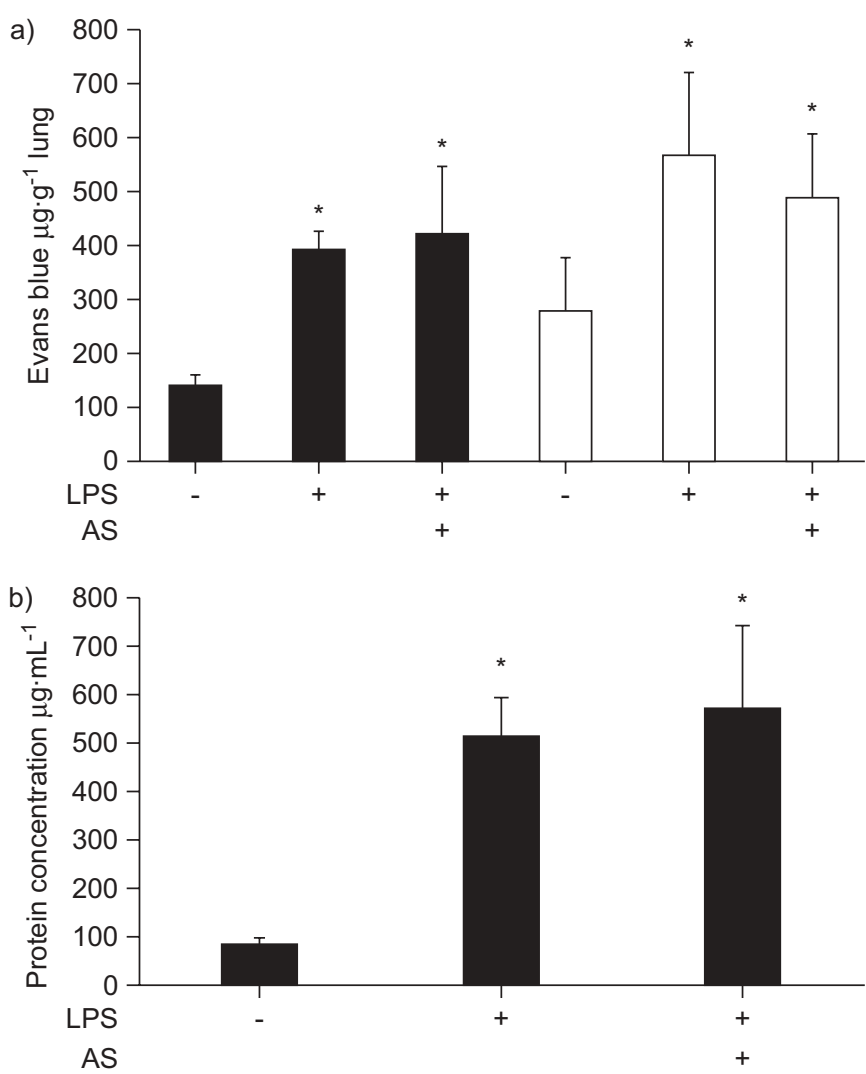

FIGURE 6. Lipopolysaccharide (LPS) inhalation induced a significant increase in microvascular permeability in wild-type $\left(394 \pm 33\right.$ versus $151 \pm 11 \mu \mathrm{g} \cdot \mathrm{g}^{-1}$ lung; $\mathrm{p}<0.05 ; \mathbf{\square})$ and phosphoinositide 3-kinase $\gamma(P / 3 K \gamma)$ gene-deficient $\left(P / 3 K \gamma^{-/-}\right)$mice $\left(568 \pm 153\right.$ versus $279 \pm 97 \mu \mathrm{g} \cdot \mathrm{g}^{-1}$ lung; $\left.\mathrm{p}<0.05 ; \square\right)$ as assessed by the extravasation of Evans blue (a). Pretreatment with AS-605240 (AS) did not reduce LPS-induced microvascular permeability in wild-type mice. In addition, inhibition of $P I 3 K \gamma$ did not affect LPS-induced protein efflux into the bronchoalveolar lavage fluid (b). Data are presented as mean $\pm S D$ from four experiments. *: $p<0.05$ versus negative control within the same group (wild-type or $P / 3 K \gamma^{-/-}$mice, respectively).

three-fold increase in intravascular PMNs in the lungs. Several reasons may have contributed to this discrepancy. 1) SMITH et al. [49] tested the role of $P I 3 K \gamma$ in P-selectin-dependent adhesion. In our model, adhesion to the pulmonary microcirculation is Pselectin-independent (unpublished observation). 2) Cell trafficking in the systemic circulation differs substantially from the pulmonary microcirculation. Adhesion in the small pulmonary capillaries occurs largely independent of adhesion molecules and chemokines. 3) SMITH et al. [49] found that PI3K $\gamma$ was essential to keep leukocytes attached to post-capillary venules within a period of $60 \mathrm{~s}$. In the lung, PMNs reside for a much longer time before they are released back to the circulation or migrate into the lung (1-2 h) [26]. Short time effects have not been investigated in the present study. 4) It is important to recognise that accumulation of PMNs in the pulmonary circulation is directly related to the migratory activity of these cells. Reduced migration into the alveolar space will increase numbers of PMNs in upstream compartments, i.e. interstitium and intravascular space.

In addition, endothelial but not leukocyte $P I 3 K \gamma$ mediated TNF- $\alpha$-induced PMN adhesion to cremaster muscle venules, 
and nonleukocyte $P I 3 K \gamma$ contributed to LPS-induced migration of PMNs into the BALF [19]. E-selectin-mediated adhesion of PNMs to cremaster muscle venules was almost completely abolished when $P I 3 K \gamma$ was absent on endothelial cells [19]. Others confirmed a role for PI3K $\gamma$ in chemokine-induced PMN transmigration but did not observe $P I 3 K \gamma$-dependent adhesion and rolling [50]. In the present study, compartmentalisation of PMN trafficking in the lung revealed that adhesion to and transmigration through the pulmonary endothelium did not require $P I 3 K \gamma$. Consistent with these findings, we found no effects when PECs were treated with AS-605240 in vitro. Although migratory activity was reduced when PI3K $\gamma$ was blocked in PMNs, the inhibitory effect of AS-605240 on neutrophil migration through an endothelial monolayer was comparable to that seen without monolayer. These studies indicate that PECs do not significantly contribute to PI3K $\gamma$ mediatied PMN migration. In contrast, blocking $\mathrm{PI} 3 \mathrm{~K} \gamma$ in human pulmonary epithelial cells significantly reduced PMN migration in an in vitro transmigration system (fig. 4c). This supports our hypothesis of a distinct role of epithelial PI3K $\gamma$ in pulmonary leukocyte trafficking.

In addition, $P I 3 K \gamma^{---}$mice had significantly higher PMN counts in the intravascular space than wild-type mice (figs $1 \mathrm{~b}$ and $2 \mathrm{a}$ ). This increased availability of intravascular neutrophils may have contributed to increased migration of PMNs through the endothelial barrier in $\mathrm{PI} 3 \mathrm{~K}^{-/-}$mice. However, transepithelial migration into the alveolar airspace was significantly reduced when $P I 3 K \gamma$ was absent. The defect was prominent in $P I 3 K \gamma^{-/-}$ mice and remained when $P I 3 K \gamma$ function on leukocytes was restored. The mechanisms that link nonleukocyte $P I 3 K \gamma-$ signalling to the recruitment of inflammatory cells are not fully understood, but PI3K-dependent activation of adhesion molecules appears to be involved. In HUVECs, cytokineinduced expression of ICAM-1 and vascular cell adhesion molecule-1 involves PI3K-signalling [51]. Others, however, demonstrated that PI3K rather suppressed the expression of adhesion molecules on endothelial cells [52]. ICAM-1 is a critical mediator in LPS-induced lung injury [7]. It is worth mentioning that ICAM-1 on alveolar and bronchial epithelium significantly contributes to inflammatory leukocyte recruitment to the lung [53]. PI3K deletion may reduce epithelial ICAM-1 expression and result in disturbed transepithelial migration that has been observed in our study. Additional mechanisms of nonleukocyte PI3K-signalling in inflammation include activation of heat shock protein 70 [54] and release of reactive oxidant species [48].

In summary, our study reveals a differentiated role of $P I 3 K \gamma$ signalling in LPS-induced PMN trafficking in the lung. Our findings point to a specific role of $P I 3 K \gamma$ for the transepithelial migration into the alveolar space that involves $P I 3 K \gamma$ on nonhaematopoietic cells. A small-molecule $P I 3 K \gamma$ inhibitor effectively reduced PMN transmigration but did not reduce LPS-induced microvascular permeability. Further investigations are required to determine its therapeutic potential in ALI.

\section{SUPPORT STATEMENT}

This study was supported by the German Research Foundation (Bonn, Germany; grant RE 1683/3-1 to J. Reutershan) and by the National Insitutes of Health, Bethesda, MD, USA (grant HL73361 to K. Ley).

\section{STATEMENT OF INTEREST}

A statement of interest for T. Rückle can be found at www.erj. ersjournals.com $/ \mathrm{misc} /$ statements.dtl

\section{REFERENCES}

1 Rubenfeld GD, Caldwell E, Peabody E, et al. Incidence and outcomes of acute lung injury. N Engl J Med 2005; 353: 1685-1693.

2 Abraham E, Carmody A, Shenkar R, et al. Neutrophils as early immunologic effectors in hemorrhage- or endotoxemia-induced acute lung injury. Am J Physiol Lung Cell Mol Physiol 2000; 279: L1137-L1145.

3 Reutershan J, Ley K. Bench-to-bedside review: acute respiratory distress syndrome - how neutrophils migrate into the lung. Crit Care 2004; 8: 453-461.

4 Ware LB, Matthay MA. The acute respiratory distress syndrome. N Engl J Med 2000; 342: 1334-1349.

5 Rubenfeld GD, Herridge MS. Epidemiology and outcomes of acute lung injury. Chest 2007; 131: 554-562.

6 Pallister I, Dent C, Topley N. Increased neutrophil migratory activity after major trauma: a factor in the etiology of acute respiratory distress syndrome? Crit Care Med 2002; 30: 1717-1721.

7 Basit A, Reutershan J, Morris MA, et al. ICAM-1 and LFA-1 play critical roles in LPS-induced neutrophil recruitment into the alveolar space. Am J Physiol Lung Cell Mol Physiol 2006; 291: L200-L207.

8 Andonegui G, Bonder CS, Green F, et al. Endothelium-derived Toll-like receptor-4 is the key molecule in LPS-induced neutrophil sequestration into lungs. J Clin Invest 2003; 111: 1011-1020.

9 Reutershan J, Morris MA, Burcin TL, et al. Critical role of endothelial CXCR2 in LPS-induced neutrophil migration into the lung. J Clin Invest 2006; 116: 695-702.

10 Cantley LC. The phosphoinositide 3-kinase pathway. Science 2002; 296: 1655-1657.

11 Deane JA, Fruman DA. Phosphoinositide 3-kinase: diverse roles in immune cell activation. Annu Rev Immunol 2004; 22: 563-598.

12 Hirsch E, Katanaev VL, Garlanda C, et al. Central role for G protein-coupled phosphoinositide 3-kinase $\gamma$ in inflammation. Science 2000; 287: 1049-1053.

13 Ruckle T, Schwarz MK, Rommel C. PI3K $\gamma$ inhibition: towards an "aspirin of the 21st century"? Nat Rev Drug Discov 2006; 5: 903-918.

14 Lionetti V, Lisi A, Patrucco E, et al. Lack of phosphoinositide 3kinase $-\gamma$ attenuates ventilator-induced lung injury. Crit Care Med 2006; 34: 134-141.

15 Uhlig U, Fehrenbach H, Lachmann RA, et al. Phosphoinositide 3$\mathrm{OH}$ kinase inhibition prevents ventilation-induced lung cell activation. Am J Respir Crit Care Med 2004; 169: 201-208.

16 Ong E, Gao XP, Predescu D, et al. Role of phosphatidylinositol 3kinase- $\gamma$ in mediating lung neutrophil sequestration and vascular injury induced by E. coli sepsis. Am J Physiol Lung Cell Mol Physiol 2005; 289: L1094-L1103.

17 Maus UA, Backi M, Winter C, et al. Importance of phosphoinositide 3-kinase $\gamma$ in the host defense against pneumococcal infection. Am J Respir Crit Care Med 2007; 175: 958-966.

18 Williams DL, Li C, Ha T, et al. Modulation of the phosphoinositide 3-kinase pathway alters innate resistance to polymicrobial sepsis. J Immunol 2004; 172: 449-456.

19 Puri KD, Doggett TA, Huang CY, et al. The role of endothelial PI3K $\gamma$ activity in neutrophil trafficking. Blood 2005; 106: 150-157.

20 Li Z, Jiang H, Xie W, et al. Roles of PLC- $\beta 2$ and $-\beta 3$ and PI3K $\gamma$ in chemoattractant-mediated signal transduction. Science 2000; 287: 1046-1049.

21 Stark MA, Huo Y, Burcin TL, et al. Phagocytosis of apoptotic neutrophils regulates granulopoiesis via IL-23 and IL-17. Immunity 2005; 22: 285-294.

22 Forlow SB, Schurr JR, Kolls JK, et al. Increased granulopoiesis through interleukin-17 and granulocyte colony-stimulating factor 
in leukocyte adhesion molecule-deficient mice. Blood 2001; 98 3309-3314.

23 Camps $\mathrm{M}$, Ruckle $\mathrm{T}$, Ji H, et al. Blockade of PI3K $\gamma$ suppresses joint inflammation and damage in mouse models of rheumatoid arthritis. Nat Med 2005; 11: 936-943.

24 Leavell KJ, Peterson MW, Gross TJ. Human neutrophil elastase abolishes interleukin-8 chemotactic activity. J Leukoc Biol 1997; 61: 361-366.

25 Weppler A, Rowter D, Hermanns I, et al. Modulation of endotoxininduced neutrophil transendothelial migration by alveolar epithelium in a defined bilayer model. Exp Lung Res 2006; 32: 455-482.

26 Reutershan J, Basit A, Galkina EV, et al. Sequential recruitment of neutrophils into lung and bronchoalveolar lavage fluid in LPSinduced acute lung injury. Am J Physiol Lung Cell Mol Physiol 2005; 289: L807-L815.

27 Reutershan J, Chang D, Hayes JK, et al. Protective effects of isoflurane pretreatment in endotoxin-induced lung injury. Anesthesiology 2006; 104: 511-517.

28 Green TP, Johnson DE, Marchessault RP, et al. Transvascular flux and tissue accrual of Evans blue: effects of endotoxin and histamine. J Lab Clin Med 1988; 111: 173-183.

29 Peng X, Hassoun PM, Sammani S, et al. Protective effects of sphingosine 1-phosphate in murine endotoxin-induced inflammatory lung injury. Am J Respir Crit Care Med 2004; 169: 1245-1251.

30 Wang LF, Patel M, Razavi HM, et al. Role of inducible nitric oxide synthase in pulmonary microvascular protein leak in murine sepsis. Am J Respir Crit Care Med 2002; 165: 1634-1639.

31 Yum HK, Arcaroli J, Kupfner J, et al. Involvement of phosphoinositide 3-kinases in neutrophil activation and the development of acute lung injury. J Immunol 2001; 167: 6601-6608.

32 Yang KY, Arcaroli J, Kupfner J, et al. Involvement of phosphatidylinositol 3-kinase $\gamma$ in neutrophil apoptosis. Cell Signal 2003; 15: 225-233.

33 Oberholzer C, Oberholzer A, Clare-Salzler M, et al. Apoptosis in sepsis: a new target for therapeutic exploration. FASEB J 2001; 15: 879-892.

34 Schwartz LM, Osborne BA. Programmed cell death, apoptosis and killer genes. Immunol Today 1993; 14: 582-590.

35 Fischer S, De Perrot M, Liu M, et al. Interleukin 10 gene transfection of donor lungs ameliorates posttransplant cell death by a switch from cellular necrosis to apoptosis. J Thorac Cardiovasc Surg 2003; 126: 1174-1180.

$36 \mathrm{Xu} \mathrm{D}$, Guthrie JR, Mabry S, et al. Mitochondrial aldehyde dehydrogenase attenuates hyperoxia-induced cell death through activation of ERK/MAPK and PI3K-Akt pathways in lung epithelial cells. Am J Physiol Lung Cell Mol Physiol 2006; 291: L966-L975.

37 Bonnans C, Fukunaga K, Keledjian R, et al. Regulation of phosphatidylinositol 3-kinase by polyisoprenyl phosphates in neutrophil-mediated tissue injury. J Exp Med 2006; 203: 857-863.

38 Bao S, Wang Y, Sweeney $\mathrm{P}$, et al. Keratinocyte growth factor induces Akt kinase activity and inhibits Fas-mediated apoptosis in A549 lung epithelial cells. Am J Physiol Lung Cell Mol Physiol 2005; 288: L36-L42.

39 Lai JP, Dalton JT, Knoell DL. Phosphatase and tensin homologue deleted on chromosome ten (PTEN) as a molecular target in lung epithelial wound repair. Br J Pharmacol 2007; 152: 1172-1184.
40 Schabbauer G, Tencati M, Pedersen B, et al. PI3K-Akt pathway suppresses coagulation and inflammation in endotoxemic mice. Arterioscler Thromb Vasc Biol 2004; 24: 1963-1969.

41 Zhang WJ, Wei H, Hagen T, et al. Alpha-lipoic acid attenuates LPSinduced inflammatory responses by activating the phosphoinositide 3-kinase/Akt signaling pathway. Proc Natl Acad Sci USA 2007; 104: 4077-4082.

42 Wrann CD, Tabriz NA, Barkhausen T, et al. The phosphatidylinositol 3-kinase signaling pathway exerts protective effects during sepsis by controlling C5a-mediated activation of innate immune functions. J Immunol 2007; 178: 5940-5948.

43 Miyahara T, Hamanaka K, Weber DS, et al. Phosphoinositide 3kinase, Src, and Akt modulate acute ventilation-induced vascular permeability increases in mouse lungs. Am J Physiol Lung Cell Mol Physiol 2007; 293: L11-L21.

44 Shiojima I, Walsh K. Role of Akt signaling in vascular homeostasis and angiogenesis. Circ Res 2002; 90: 1243-1250.

45 Ispanovic E, Haas TL. JNK and PI3K differentially regulate MMP-2 and MT1-MMP mRNA and protein in response to actin cytoskeleton reorganization in endothelial cells. Am J Physiol Cell Physiol 2006; 291: C579-C588.

46 Maffucci T, Piccolo E, Cumashi A, et al. Inhibition of the phosphatidylinositol 3-kinase/Akt pathway by inositol pentakisphosphate results in antiangiogenic and antitumor effects. Cancer Res 2005; 65: 8339-8349.

47 Madge LA, Pober JS. A phosphatidylinositol 3-kinase/Akt pathway, activated by tumor necrosis factor or interleukin-1, inhibits apoptosis but does not activate NFKB in human endothelial cells. J Biol Chem 2000; 275: 15458-15465.

48 Frey RS, Gao X, Javaid K, et al. Phosphatidylinositol 3-kinase $\gamma$ signaling through protein kinase $\mathrm{C} \zeta$ induces NADPH oxidasemediated oxidant generation and NF- $\mathrm{\kappa B}$ activation in endothelial cells. I Biol Chem 2006; 281: 16128-16138.

49 Smith DF, Deem TL, Bruce AC, et al. Leukocyte phosphoinositide-3 kinase $\gamma$ is required for chemokine-induced, sustained adhesion under flow in vivo. I Leukoc Biol 2006; 80: 1491-1499.

50 Liu L, Puri KD, Penninger JM, et al. Leukocyte PI3K $\gamma$ and PI3K $\delta$ have temporally distinct roles for leukocyte recruitment in vivo. Blood 2007; 110: 1191-1198.

51 Min JK, Kim YM, Kim SW, et al. TNF-related activation-induced cytokine enhances leukocyte adhesiveness: induction of ICAM-1 and VCAM-1 via TNF receptor-associated factor and protein kinase C-dependent NF- $\mathrm{kB}$ activation in endothelial cells. J Immunol 2005; 175: 531-540.

52 Wang JG, Mahmud SA, Nguyen J, et al. Thiocyanate-dependent induction of endothelial cell adhesion molecule expression by phagocyte peroxidases: a novel HOSCN-specific oxidant mechanism to amplify inflammation. J Immunol 2006; 177: 8714-8722.

53 Floreani AA, Wyatt TA, Stoner J, et al. Smoke and C5a induce airway epithelial intercellular adhesion molecule-1 and cell adhesion. Am J Respir Cell Mol Biol 2003; 29: 472-482.

54 Rafiee P, Theriot ME, Nelson VM, et al. Human esophageal microvascular endothelial cells respond to acidic $\mathrm{pH}$ stress by PI3K/AKT and p38 MAPK-regulated induction of Hsp70 and Hsp27. Am J Physiol Cell Physiol 2006; 291: C931-C945. 